\title{
Ex vivo machine perfusion: current applications and future directions in liver transplantation
}

\author{
Julian Michelotto ${ }^{1} \cdot$ Joseph M. G. V. Gassner ${ }^{1} \cdot$ Simon Moosburner ${ }^{1} \cdot$ Vanessa Muth $^{1} \cdot$ Madhukar S. Patel $^{2}$. \\ Markus Selzner $^{2} \cdot$ Johann Pratschke $^{1} \cdot$ Igor M. Sauer $^{1} \cdot$ Nathanael Raschzok ${ }^{1,2}$ (D)
}

Received: 26 June 2020 / Accepted: 21 July 2020 / Published online: 20 November 2020

(C) The Author(s) 2020

\begin{abstract}
Background Liver transplantation is the only curative treatment option for end-stage liver disease; however, its use remains limited due to a shortage of suitable organs. In recent years, ex vivo liver machine perfusion has been introduced to liver transplantation, as a means to expand the donor organ pool.

Purpose To present a systematic review of prospective clinical studies on ex vivo liver machine perfusion, in order to assess current applications and highlight future directions.

Methods A systematic literature search of both PubMed and ISI web of science databases as well as the ClinicalTrials.gov registry was performed.

Results Twenty-one articles on prospective clinical trials on ex vivo liver machine perfusion were identified. Out of these, eight reported on hypothermic, eleven on normothermic, and two on sequential perfusion. These trials have demonstrated the safety and feasibility of ex vivo liver machine perfusion in both standard and expanded criteria donors. Currently, there are twelve studies enrolled in the clinicaltrials.gov registry, and these focus on use of ex vivo perfusion in extended criteria donors and declined organs.

Conclusion Ex vivo liver machine perfusion seems to be a suitable strategy to expand the donor pool for liver transplantation and holds promise as a platform for reconditioning diseased organs.
\end{abstract}

Keywords Machine perfusion $\cdot$ Liver transplantation $\cdot$ Clinical application $\cdot$ Systematic literature review

\begin{tabular}{|c|c|}
\hline \multicolumn{2}{|c|}{ Abbreviations } \\
\hline EAD & Early allograft dysfunction \\
\hline PNF & Primary nonfunction \\
\hline DBD & Donation after brain death \\
\hline DCD & Donation after circulatory death \\
\hline IRI & Ischemia-reperfusion injury \\
\hline
\end{tabular}

Nathanael Raschzok

nathanael.raschzok@charite.de

1 Charité - Universitätsmedizin Berlin, Department of Surgery,

Experimental Surgery, corporate member of Freie Universität Berlin,

Humboldt- Universität zu Berlin and Berlin Institute of Health,

Campus Charité Mitte | Campus Virchow-Klinikum,

Berlin, Germany

2 Department of Surgery, Abdominal Transplant and HPB Surgery, Ajmera Family Transplant Centre, Toronto General Hospital, Toronto, ON, Canada

\begin{tabular}{|c|c|}
\hline SCS & Static cold storage \\
\hline HMP & Hypothermic machine perfusion \\
\hline HOPE & $\begin{array}{l}\text { Hypothermic oxygenated } \\
\text { machine perfusion }\end{array}$ \\
\hline D-HOPE & $\begin{array}{l}\text { Dual hypothermic oxygenated } \\
\text { machine perfusion }\end{array}$ \\
\hline HLS & Hospital length of stay \\
\hline pSCS & post-Static cold storage \\
\hline NEVLP & $\begin{array}{l}\text { Normothermic ex vivo liver } \\
\text { machine perfusion }\end{array}$ \\
\hline
\end{tabular}

\section{Introduction}

Liver transplantation is the only curative treatment option for acute liver failure and advanced hepatobiliary malignancies. Unfortunately, this therapy is limited by the supply of suitable donor livers for transplantation [1], as reflected in high waitlist mortality [2]. Despite much progress in transplantation, static 
cold storage (SCS) remains the standard technique for graft preservation after procurement, as it reduces the sequelae of ischemic injury $[3,4]$.

To ameliorate the gap between supply and demand for liver transplantation, the use of marginal livers has increased [5-10]. Marginal liver grafts may be obtained from elderly donors, those with clinical factors predisposing them to hepatic steatosis, or from donation after circulatory death (DCD), compared with traditional donation after brain death (DBD) [11-15]. Elderly donors, most often defined as originating from donors above the age of 60 [16, 17], run a risk of impaired metabolic function and cellular regeneration due to a life-long exposure to hepatotoxic agents and fibrotic remodeling [18]. With regard to hepatic steatosis, it is defined by the presence of triglyceride droplets in more than 5\% of hepatocytes of either small (microvesicular) or large (macrovesicular) composition [19]. While grafts affected by mild macrovesicular steatosis $(<30 \%)$ are considered suitable for transplantation [20], moderate to severe steatosis was revealed as independent prognostic factor for poor postoperative outcomes [21, 22]. Although the pathophysiologic mechanisms are not completely understood, these fat deposits are often a result of genetic predisposition combined with high calorie intake, alcohol abuse, or old age $[23,24]$. Hepatic steatosis and fibrotic remodeling of the liver are hypothesized to lead to decreased metabolic function, obstructed microvascular perfusion, and a greater susceptibility of ischemia-reperfusion injury (IRI) after transplantation [25, 26]. Lastly, DCD organs are retrieved after a period of reduced and ultimately stopped circulation, inherently resulting in increased warm ischemia until flushing of the organ with cold perfusion solution. Depending on the preexisting condition of the organ, this may lead to distinct cellular injury and ischemiarelated damage of non-parenchymal cells such as Kupffer cells and cholangiocytes. Taken together, the use of marginal donor grafts is associated with an increased risk of clinically significant postoperative complications such as early allograft dysfunction (EAD), primary nonfunction (PNF), or ischemic cholangiopathy [11, 27-34].

Historically, liver machine perfusion had been considered for organ preservation, but early approaches were not widely adopted. Recently, with much technological progress being made, there is a renewed interest to implement this technique to not only assess, but also to improve the quality of liver grafts (Fig.1) [35-37].

As such, one of the primary goals of ex vivo liver machine perfusion is to mitigate the effects of graft IRI [38, 39]. Through perfusion at different temperatures, ranging from hypothermic $\left(+4\right.$ to $\left.+10^{\circ} \mathrm{C}\right)$ to subnormothermic $\left(+15^{\circ} \mathrm{C}\right.$ to $\left.30{ }^{\circ} \mathrm{C}\right)$ and to normothermic $\left(37^{\circ} \mathrm{C}\right)$ [40], graft metabolites can be flushed, nutrient supply optimized, and microvascular circulation maintained. [3, 4, 41, 42]. In the last decade, several studies ranging from proof-of-concept animal experiments to randomized trials have been published on the different modes of ex vivo liver machine perfusion. The aim of this systematic review is to provide a summary of the literature on ex vivo liver machine perfusion, with a focus on current clinical application and an outlook on future directions in transplantation. Mechanistic aspects of liver machine perfusion and experimental studies in animal models were thus excluded as they were outside the scope of this review.

\section{Methods}

\section{Search strategy}

A systematic literature review was performed following the Preferred Reporting Items for Systematic reviews and MetaAnalyses for Protocols 2015 (PRISMA-P) (Fig. 2). A wideranging screening of the National Library of Medicine Database and the ISI Web of Science Database was performed on April 7, 2020, and last updated on June 18, 2020, in order to identify literature on liver preservation using machine perfusion (MP) as an alternative to SCS in human orthotopic liver transplantation.

The following search queries were performed:

1) "liver AND machine AND perfusion AND human"

2) "liver transplantation AND perfusion AND human"

3) "liver transplantation AND perfusion AND CLINICAL TRIAL"

4) "liver transplantation AND normotherm* AND human"

5) "liver transplantation AND hypotherm* AND human"

Additionally, the ClinicalTrials.gov registry of the US National Library of Medicine was searched on April 9, 2020, for the following MeSH terms:

"Machine Perfusion AND Liver Transplantation"

\section{Inclusion criteria}

Articles meeting inclusion criteria for this review were published prospective studies using any type of ex vivo machine perfusion device for organ preservation in liver transplantation. Editorials, letters, reviews, case reports, conference abstracts, and video articles were excluded. As were follow-up studies on already published grafts, perfusate samples, or liver biopsies which reported no further information on peri- or postoperative outcomes of the respective recipients. With regard to clinical trials, inclusion criteria involved any kind of trials on transplantation of liver grafts after ex vivo machine perfusion with the following recruitment statuses: "recruiting," "active, not recruiting," "not yet recruiting," or "enrolling by invitation." 
Static Cold Storage (SCS)
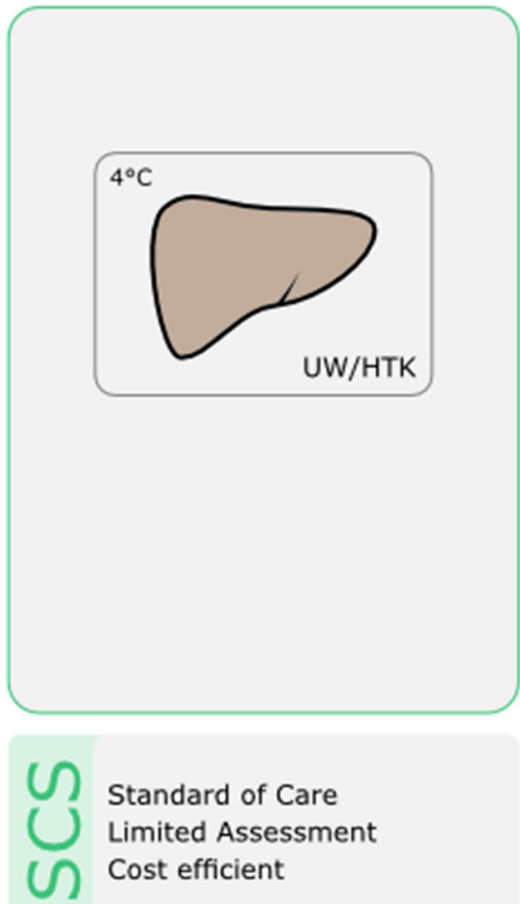

Hypothermic machine perfusion (HMP)

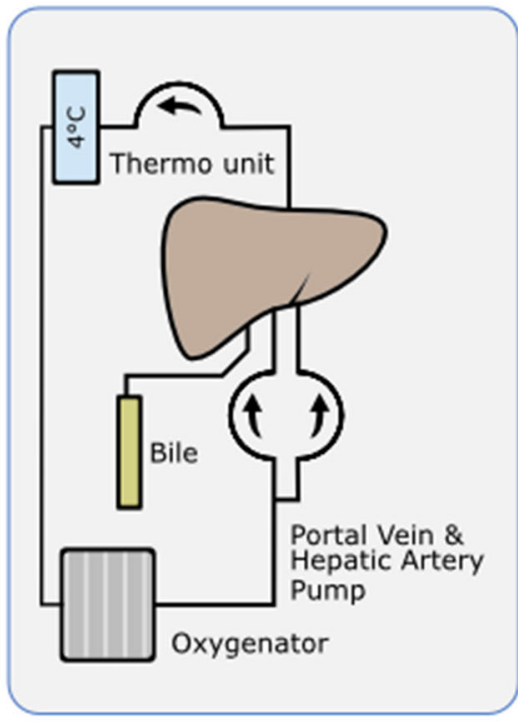

Improved Storage

Ease of Use

Assessment

by surrogate parameters
Normothermic ex vivo liver machine perfusion (NEVLP)
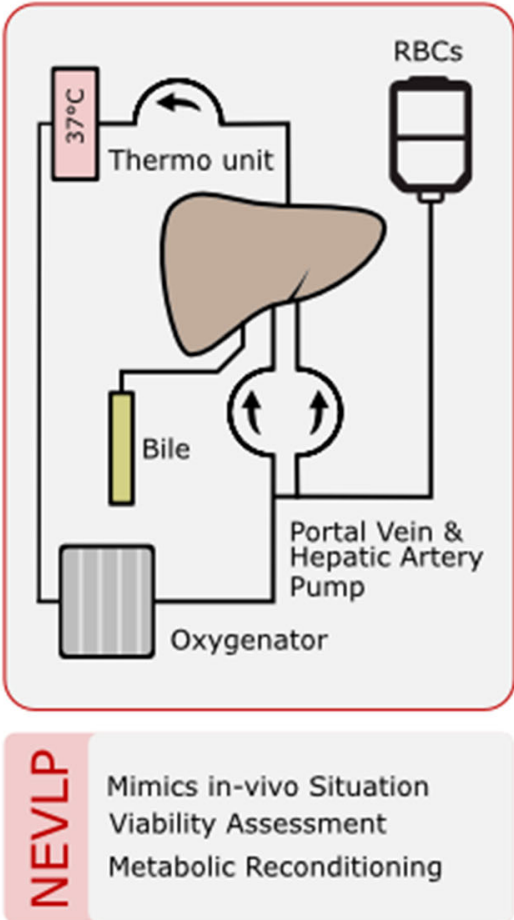

Mimics in-vivo Situation Viability Assessment

Metabolic Reconditioning

Fig. 1 Preservation methods for liver transplantation with static cold storage (SCS), hypothermic machine perfusion (HMP), and normothermic ex vivo liver machine perfusion (NEVLP) and their respective advantages

\section{Data extraction}

A two-stage independent screening method was applied by two of the authors (JM and JG). In case of discordance, the corresponding author NR was consulted, and consensus was made via discussion. During stage one of data extraction, the titles and abstracts of all retrieved records were reviewed and unsuitable studies were excluded. During stage two, full text articles of remaining studies were read carefully and assessed for inclusion criteria. For the identification of clinical trials, the study description was reviewed by NR and MP and results discussed with the remaining authors. Extracted data were reviewed and analyzed by all authors.

\section{Results}

\section{General information}

Systematic literature search of the National Library of Medicine database and the ISI Web of Science database identified 1.956 unique records. Based on to title and abstract, 1.887 papers could be removed, leaving 69 articles for full text analysis. Of these, 48 publications did not meet inclusion criteria. Two of the identified publications were video-articles and therefore excluded. One publication using hypothermic oxygenated perfusion (HOPE) was removed given that its primary focus was on the evaluation of the safety and feasibility of normothermic regional perfusion prior to HOPE in DCD donors with extended warm ischemic times rather than the assessment of this technique for the purpose of preservation. Further five studies were identified as follow-up studies on perfusate, liver or bile duct samples of pre-published clinical trials and consequently excluded. Taken together, 21 publications on prospective clinical trials using ex vivo liver machine perfusion for graft preservation or graft assessment in liver transplantation were identified (Fig. 3). Eight reported on hypothermic (Table 1), eleven on normothermic (Table 2), and two on sequential perfusion (Table 3). Of note, no clinical trial was identified evaluating the use of subnormothermic machine perfusion.

With regard to currently registered studies, query of ClinicalTrials.gov identified a total number of 22 trials, out of which 12 met the inclusion criteria (Table 4). One clinical trial was excluded as it was primarily focused on developing a viability index for liver machine perfusion. The other nine trials were either completed or had unknown status. Out of the active studies, four were focused on hypothermic liver machine perfusion, while seven addressed normothermic machine perfusion. Sequential hypo- and normothermic perfusion is being evaluated in one ongoing trial. 
Fig. 2 Flowchart of the performed systematic literature research

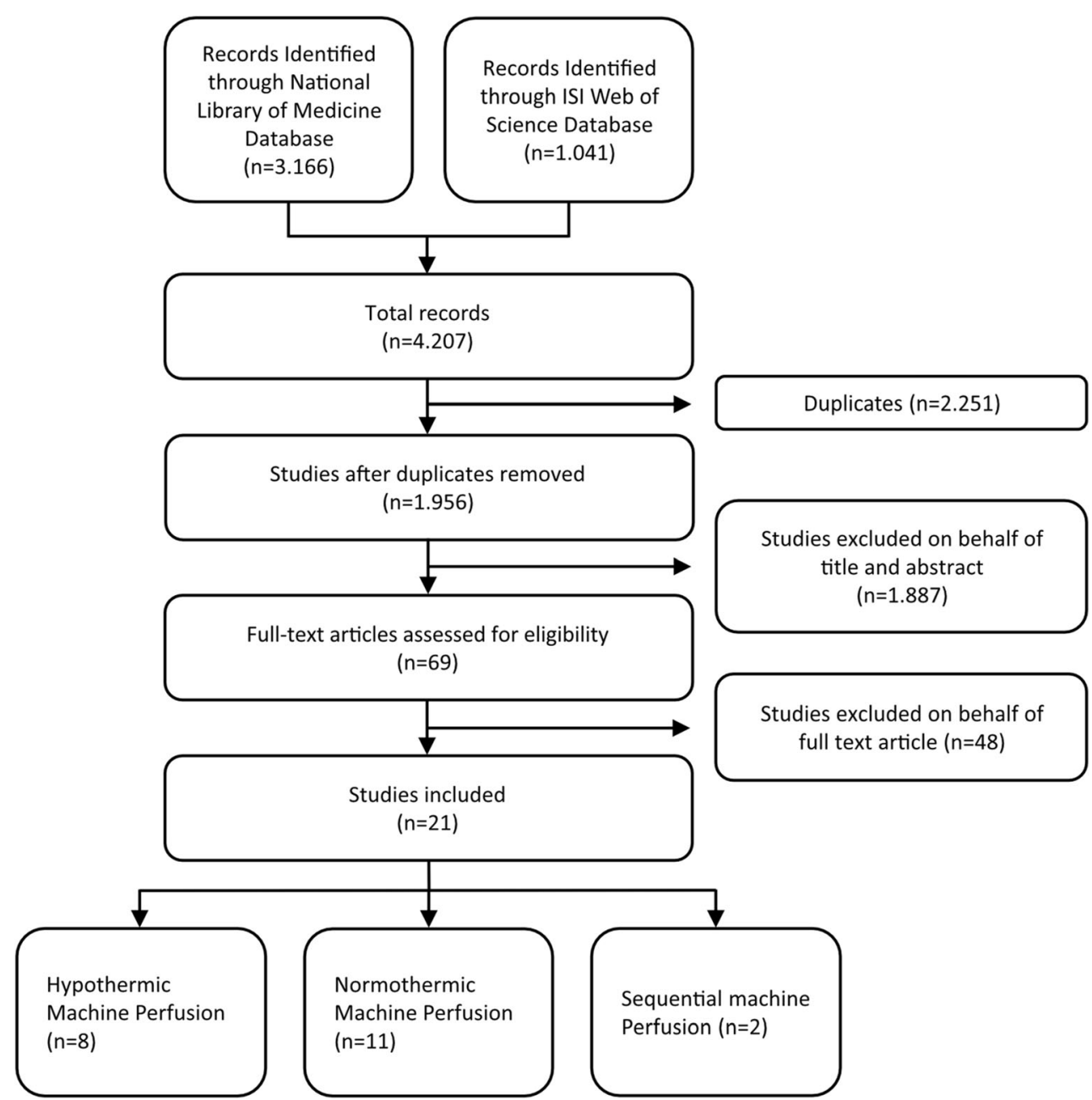

\section{Hypothermic machine preservation}

Based on perfusion technique, such as single- versus doublevessel perfusion and whether active oxygenation of the perfusate is performed, hypothermic machine preservation can be categorized as follows:

- HMP: hypothermic machine perfusion

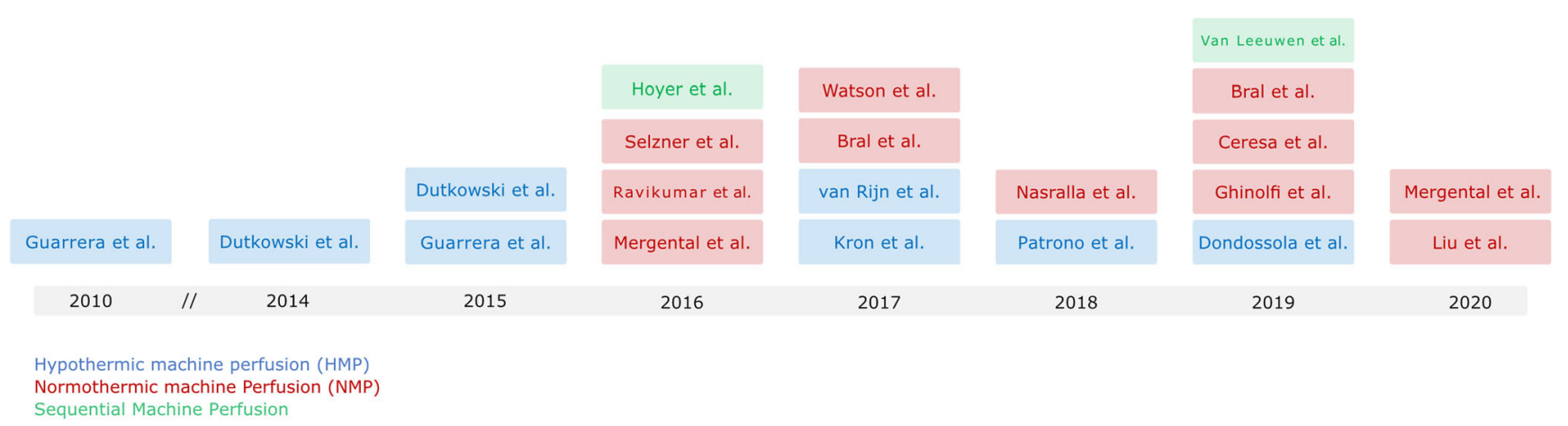

Fig. 3 Time line of published clinical trials involving liver machine perfusion, color-coded according to applied mode of perfusion with hypothermic machine perfusion (HMP, blue), normothermic ex vivo liver machine perfusion (NEVLP, red) and sequential machine perfusion (green)
- HOPE: hypothermic oxygenated machine perfusion

- D-HOPE: dual hypothermic oxygenated machine perfusion

In clinically used HMP and D-HOPE, liver grafts are perfused throughout the portal vein and the hepatic artery simultaneously, classifying them as double-vessel systems [43-47]. A single vessel approach is followed in HOPE, with organ 
perfusion exclusively via the portal vein [48-50]. While in HOPE and D-HOPE active oxygenation of the perfusate is performed [43-45, 48-50], it is omitted in HMP [46, 47].

The first prospective clinical trial investigating the role of HMP in human liver transplantation was reported by Guarrera et al. In 2010 [46], a total of 20 patients receiving standard liver grafts after HMP were compared with a matched cohort of patients undergoing liver transplantation after SCS. Following the nomenclature proposal for ex vivo liver machine perfusion published by Karangwa et al., the approach used can be classified as post-static cold storage HMP (pSCSHMP), as HMP was initiated after graft arrival in SCS at the study center, with initial SCS times exceeding 3 hours [40]. For hypothermic dual vessel perfusion, a modified Medtronic Portable Bypass System was used, creating continuous flow through the hepatic artery and the portal vein. Although no active oxygenation of the perfusate (Vasosolß) was performed, the authors reported stable oxygen pressures throughout the perfusion (mean 137.2 $\pm 4.8 \mathrm{mmHg}$ ). Within this study, no case of PNF occurred; EAD was observed in 1 patient in the HMP group and in 5 patients in control group $(p=0.08)$. One-year patient and graft survival were $90 \%$ in both groups, with no death related to graft function. However, the HMP group had significantly shorter hospital length of stay (HLS) $(p=0.006)$, and significantly lower levels of post-operative peak aspartate aminotransferase (AST) $(p=$ $0.011)$, peak alanine aminotransferase (ALT) $(p=0.044)$, total bilirubin $(p=0.042)$, and serum creatinine $(p=0.013)$ [46]. After safety and feasibility was shown, the group expanded their inclusion criteria on investigating the role of pSCS-HMP in the transplantation of ECD grafts: in 2015, Guarrera et al. published the outcomes of 31 "orphan" ECD grafts transplanted after pSCS-HMP compared with a cohort of matched SCS liver grafts [47]. Included organs were defined as ECD by either donor age above 65 years, hepatitis $\mathrm{C}$ virus positivity with $15 \%$ macrosteatosis, greater than $25 \%$ macrovesicular steatosis by biopsy, or evidence of significant donor ischemic injury (donor serum AST or ALT > 1000 IU/ L) at the time of organ offer. Additionally, the term "orphan" was coined, to indicate that included grafts were either declined by all centers of their originating UNOS Region, or by all centers of the UNOS Region 9, except the study center. The study reported the occurrence of PNF in one patient of the HMP group and in two patients of the control group ( $p=$ 0.612 ), with 6 cases of EAD observed in the HMP group and 9 cases in the control subjects $(p=0.384)$. Three cases of vascular complications occurred in the HMP group and two cases in the SCS group, with a 1-year survival of $83.8 \%$ and $80.0 \%$, respectively. Concerning biliary complications, significantly less cases were observed in the HMP-group $(p=0.001)$. Subgroup analyses showed that especially the occurrence of biliary strictures, as a cause for a biliary complication, differed between groups $(p=0.031)$. Patients in the 
HMP group had a significantly shorter HLS ( $p=0.001)$, with lower peak serum ALT on post-operative day (POD) 1 ( $p=$ $0.049)$ and lower serum creatinine on POD $5(p=0.02)$ [47]. No adverse events due to perfusion device malfunction occurred in the reported studies [46, 47].

HOPE was first introduced into clinical practice in 2014, as a series of 8 DCD liver transplantations published by Dutkowski et al. [48]. The initial trial was performed as an initiative to reintroduce DCD at the University Hospital of Zürich (Switzerland), after an almost decade long hiatus of law changes. Starting with the first available DCD liver graft, a preservation protocol including HOPE was applied, with the intention to prevent adverse outcomes. Using an Organ Assist ${ }^{\circledR}$ ECOPS device, grafts were perfused solely via the portal vein with oxygenated UW gluconate solution at pressures below $3 \mathrm{mmHg}$. Six-month graft survival was $100 \%$, with no case of PNF, delayed graft function, intrahepatic biliary cholangiopathy, or hepatic artery thrombosis, although two cases of extrahepatic biliary complications were observed [48]. For better evaluation of the impact of HOPE in DCD liver grafts, an international-matched case analysis was published by Dutkowski et al. the following year, comparing the outcomes of $n=25$ HOPE-treated DCD liver grafts with a matched cohort of $n=50$ SCS DCD and $n=50$ SCS DBD liver transplants [49]. Transplantation of HOPE-treated grafts was once again performed at the University Hospital of Zürich, while data of SCS DCD transplantations was obtained from the transplantation programs of Rotterdam (NL) and Birmingham (UK). Primary endpoints of the study included the incidence and severity of biliary complications within the first year after transplantation. Secondary endpoints were related to liver IRI and function and graft survival. Total cold preservation time reported was significantly shorter in the HOPE group $(p=0.002)$. Comparing post-operative outcomes, HOPE-treated DCD grafts developed less cases of EAD $(p=0.046)$ and showed decreased levels of peak AST $(p=0.04)$, peak ALT $(p=0.02)$, and peak Bilirubin $(p=$ $0.016)$ compared with SCS DCD controls. In the HOPE group, no case of PNF occurred. Regarding extrahepatic biliary complications, no differences were observed between groups, although significantly less cases of intrahepatic cholangiopathy were noted in HOPE-treated DCD grafts $(p=0.013)$. Overall, 1-year graft survival was $90 \%$ in HOPE-treated, compared with $69 \%$ in SCS DCD livers $(p=$ 0.035 ) [49]. Additionally, outcomes were compared with a matched cohort of 50 DBD SCS liver transplantations, which showed no significant differences across the analyzed endpoints [49].

A third study applying HOPE, also performed by the Zürich group, was published in 2017: Kron et al. reported a series of 6 liver transplantations using HOPE-treated, steatotic liver grafts [50]. This pilot trial was initiated to evaluate promising observations made in rodent experiments published within the same article. Grafts had a median macrovesicular steatosis of $30 \%$ (20-30) with 5 livers being retrieved from DCD donors. Recipient Lab-MELD score ranged from 6 to 16. [50]. There were no cases of PNF and all patients were alive at 1-year follow-up. Compared with a cohort of DBD SCS steatotic grafts, matched for donor and recipient age as well as total preservation time, HOPE treatment showed lower ALT post reperfusion $(p=0.04)$ with higher rates of 1 -year patient survival $(p=0.04)$ [50].

The first study evaluating end-ischemic D-HOPE in human DCD liver transplantation was published 2017 by Van Rijn et al. from the Netherlands [45]. The authors reported a series of 10 patients undergoing liver transplantation of DCD grafts treated with end-ischemic D-HOPE. In the trial, a Liver Assist (Organ Assist, Groningen, the Netherlands) device was used for pulsatile perfusion of the hepatic artery and creation of a continuous flow through the portal vein. Perfusate consisted of 41 of UW Machine Perfusion Solution, supplemented with $3 \mathrm{mmol} / \mathrm{l}$ glutathione and was oxygenated at pressures above $450 \mathrm{mmHg}$, by two hollow fiber membrane oxygenators [45]. The study reported patient and graft survivals of $100 \%$ after 6 months and 1 year. Comparing outcomes with a matched cohort of 20 SCS DCD liver transplantations, peak serum ALT levels were significantly lower in recipients of DHOPE-treated grafts $(p=0.006)$, as was serum bilirubin at POD7 $(p=0.044)$. No significant differences in intensive care unit $(p=0.475)$ or HLS $(p=0.88)$ were observed. Of note, 3 patients of the D-HOPE group developed post reperfusion hypokalemia $(p=0.03)$, without significant differences in other postoperative complications [45].

Recently, in 2018 and 2019, two further articles reported the use of D-HOPE in liver transplantation [43, 44]. Dondossola et al. utilized D-HOPE in 5 DCD grafts and 2 DBD grafts, which required prolonged preservation time [44]. Patrono et al. reported the use of D-HOPE in 4 cases of higher risk DBD liver transplantation either due to donor issues, severity of liver disease in the recipient, or both [43]. Both studies used the Liver Assist device for organ perfusion and D-HOPE was initiated after a preceding period of SCS [43, 44]. Dondossola et al. observed 3 cases of post reperfusion syndrome (PRS) with no cases of PNF. EAD occurred in 2 cases (1 DCD and 1 DBD graft). One DBD graft included was discarded after additional viability assessment through normothermic ex vivo liver machine perfusion (NEVLP). After a median follow-up of 270 (106582) days, patient and graft survivals were $100 \%$ with no occurrence of biliary complications [44]. Similar outcomes were reported by Patrono et al. with patient and graft survivals of $100 \%$ at 6 -month follow-up. There was no clinical evidence of ischemic cholangiopathy. In their trial, they 


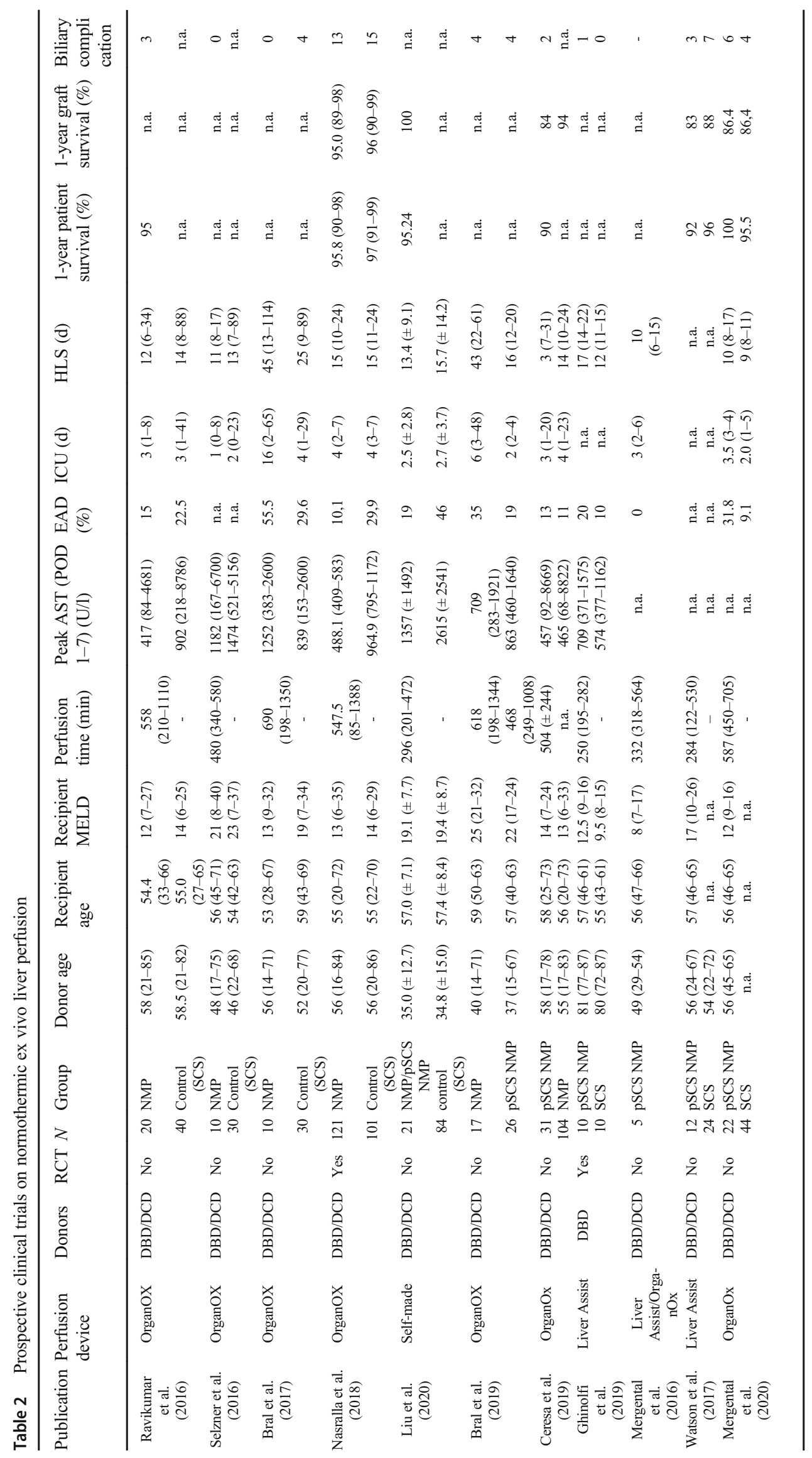


experienced one case of post reperfusion syndrome and two cases of EAD [43].

\section{Normothermic ex vivo liver machine perfusion}

NEVLP was first introduced into clinical practice through a Phase-I clinical trial performed by Ravikumar et al. in 2016 [51] and shortly followed by two Northern American studies published by Selzner et al. in 2016 and Bral et al. in 2017 [52, 53]. For organ perfusion, the portable OrganOx Metra ${ }^{\circledR}$ device was used in all studies, allowing normothermic perfusion of the portal vein and hepatic artery simultaneously [51-53]. Perfusate consisted of Gelofusine ${ }^{\circledR}$ in the trials of Ravikumar et al. and Bral et al. [51, 53], while Selzner et al. utilized Steen solution [52]. For oxygen carriage, three units of packed red blood cells were added to the perfusate in all trials [51-53]. Perfusion was initiated after organ retrieval and back table preparation at the donor center and not preceded by a period of SCS. DCD and standard DBD donors were eligible for inclusion in all studies, although the percentage of utilized DCD grafts was higher in the trial of Bral et al. (40\% versus $20 \%$ in the studies of Selzner et al. and Ravikumar et al.) [51-53]. The primary objective of all studies was the evaluation of the safety and the feasibility of NEVLP in human liver transplantation. In total, NEVLP of 42 grafts was reported through these trials, of which 39 were successfully transplanted [51-53]. One graft was lost in the Bral et al. study due technical error (an obscure portal vein twist prevented successful NEVLP) [53]. Two grafts reported by Selzner et al. were discarded due to poor performance during NEVLP in the context of marginal donor characteristics or anatomic unsuitability for transplantation [52]. No case of PNF was reported throughout the trials with a $100 \%$ 30-day patient and graft survival [51-53]. Follow-up was limited by a three-month interval by Selzner et al. in which no case of biliary complication or graft failure was observed [52]. Bral et al. reported a 6-month follow-up, with no incidence of biliary complication and a patient survival of $89 \%$ [53]. Sixmonth and 1-year patient survival reported by Ravikumar et al. were $100 \%$ and $95 \%$, respectively [51]. Intensive care unit stay and HLS of patients receiving NEVLP preserved grafts were not significantly different compared with matched SCS controls in the studies performed by Selzner et al. and Ravikumar et al. [51, 52], while they were longer in the trial performed by Bral et al. (ICU $p=0.004$; HLS $p=0.01$ ) [53]. Finally, Ravikumar et al. reported lower peak AST levels in patients undergoing transplantation of NEVLP preserved grafts compared with a SCS matched cohort $(p=0.034)$ [51].

In 2018, a landmark study in the field of NEVLP was published by Nasralla et al., reporting the first multicenterrandomized controlled trial, comparing NEVLP with SCS [54]. In this study, $n=334$ liver grafts were randomized to either NEVLP or SCS, leading to the successful transplantation of 121 NEVLP and 101 SCS liver grafts. Seven transplant centers from four different European countries participated in the study. For graft perfusion, the OrganOx Metra ${ }^{\circledR}$ device was used. Of the included grafts, $37.1 \%$ were retrieved from DCD donors in the NEVLP arm and $36.6 \%$ in the SCS-arm [54]. The study met its primary endpoint regarding recipient peak AST levels post transplantation, showing a reduction of peak levels by $49.4 \%$ in the NEVLP group $(p<0.001)$. Subgroup analyses showed that the benefit of NEVLP, regarding peak AST, was higher for DCD grafts $(p=0.012)$. Compared with respective grafts of the SCS-arm, utilization of NEVLP reduced the geometric mean peak AST levels by $73.3 \%$ in DCD grafts $(p<0.001)$ and $40.2 \%$ in DBD grafts $(p=0.001)$. The odds reported for developing EAD were $74 \%$ lower in the NEVLP group (12 out of 119) compared with the SCS-group (29 out of 97) $(p<0.001)$, as were median serum Bilirubin levels $(p=$ $0.029)$ [54]. No differences were reported regarding intensive care unit or HLS. Furthermore, 1-year patient and graft survival were similar, with patient survival of $95.8 \%$ vs. $97 \%$ and graft survival of $95 \%$ vs. $96 \%$ in the NEVLP and the SCS group, respectively [54]. One case of PNF occurred in the study and was in the NEVLP group. Notably, a significantly lower amount of discard was noted in the NEVLP arm compared with the SCS arm $(p=0.008)$, with longer median total preservation times in livers undergoing NEVLP $(p<0.001)$ [54].

Similar results, regarding the incidence of EAD and peak AST levels, were reported by a non-randomized phase one trial published by Liu et al. in 2020 [55]. The trial was carried out with the purpose of evaluating fresh frozen plasma as perfusate, along with the demonstration of safety and feasibility for the use of a non-commercial, institutional developed perfusion device [55]. NEVLP was performed in 21 liver grafts of which $38 \%$ were obtained from DCD donors. The perfusion device was carried to the retrieval site in 6 cases, while in the remainder, perfusion was started upon graft arriv$\mathrm{al}$ at the transplant center in SCS. A maximum of $4 \mathrm{~h}$ cold ischemia time before NEVLP was limited by the study protocol [55]. Using a 1:4 historical matched cohort, post-transplant outcomes demonstrated a lower incidence of EAD in the NEVLP group ( $19 \%$ vs. $46 \% ; p=0.02)$ and lower levels of peak AST $(p=0.001)$, peak ALT $(\mathrm{p}=0.001)$, and total Bilirubin on POD7 $(p=0.001)$ were reported in the NEVLP group. One-year patient survival was reported $95.23 \%$ [55].

Relevant obstacles for introduction of NEVLP in clinic practice included logistical challenges of perfusion device transport accompanied by trained staff, as well as higher material costs compared with SCS [4]. While hypothermic machine preservation approaches were applied end ischemic from their first introduction into clinic use [46, 47], NEVLP original premise was to avoid preceding periods of SCS, thus requiring transport of the NEVLP device to the organ retrieval 


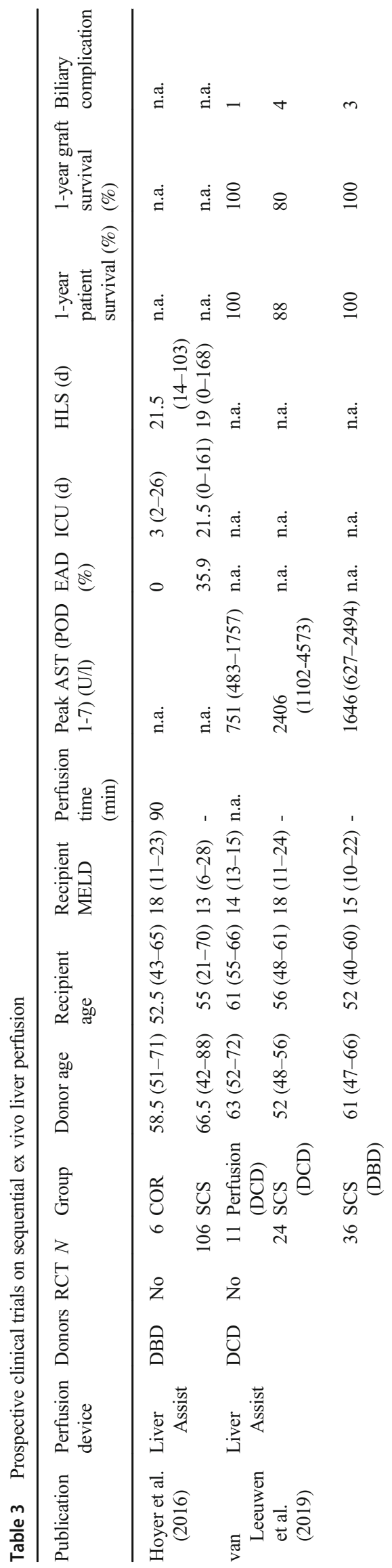

sites [51-54]. Rationale for this approach was supported by a porcine study, showing inferior graft function when delaying initiation of NEVLP [56]. In order to assess the preservation benefit of NEVLP, when accompanied by a previous period of SCS, two trials were published in 2019 comparing immediate initiation of NEVLP with a pSCS-NEVLP approach [57, 58]: Bral et al. reported a single-center nonrandomized trial, in which 17 locally procured livers, with initiation of NEVLP immediately after graft retrieval, were compared with 26 livers retrieved from distant sites, with initiation of NEVLP after graft transportation to the study center in SCS [57]. The principle of initiating NEVLP after graft arrival at the transplant center was coined "back to base" and performed to allow easier complementation of NEVLP. In the trial, 10 (23\%) grafts were obtained from DCD donors of whom 4 were in the local NEVLP and 6 in the "back-to-base" group. SCS times in the "back to base" group were significantly longer compared with the local NEVLP subjects $(p=0.001)$ with similar periods of NEVLP $(p=0.19)$. Total preservation times tended to be longer in the "back-to-base group" without reaching significance $(p=0.06)$ [57]. The primary outcome, 30-day patient and graft survival, was $100 \%$ in both groups. Furthermore, no significant difference regarding patient and graft survival at 3- and 6-month $(p=0.1)$, incidence of EAD $(p=0.29)$, peak levels of liver function parameters in the first postoperative week (AST $p=0.63$; ALT $p=0.95$; Bilirubin $p=0.43$; INR $p=0.95)$, or biliary complications $(p=0.69)$ was observed [57]. Interestingly the intensive care unit and HLS were shorter in the "back to base" group (ICU $p=$ 0.004; HLS $p=0.001)$. Comparing the overall experience of 43 NEVLP liver transplantations reported in the trial with a matched cohort of 86 SCS grafts, the group reported similar results to those seen previously [51, 54], observing significantly lower peak AST levels in the first post-operative week in patients undergoing transplantation after NEVLP $(p=$ 0.04). Furthermore, NEVLP had the logistical advantage of having more transplantations during the daytime compared with the SCS controls $(p=0.04)$. [57].

In the same year, a separate trial investigating the feasibility of pSCS-NEVLP was published by Ceresa et al. [58]. In the multicenter study, pSCS-NEVLP was performed in 30 grafts obtained from DBD (74\%) and DCD (26\%) donors. This was compared with a cohort of 104 livers preserved by continuous NEVLP. The cases used for comparison were part of the NEVLP group, reported by Nasralla et al. in 2018. The study showed safety and feasibility for pSCS-NEVLP with regard to 30-day graft survival (94\%) [58]. Furthermore, no significant differences in post-transplant outcomes, concerning serum peak AST levels $(p=0.92)$, incidence of $\operatorname{EAD}(p=0.75)$, post reperfusion syndrome $(p=0.99)$, major complications (Clavien-Dindo $\geq \mathrm{IIIb})(\mathrm{p}=0.99)$, and hospital $(p=0.88)$ or intensive care unit $(p=0.93)$ length of stay, were observed. One-year graft survival was $84 \%$ and similar to the control 


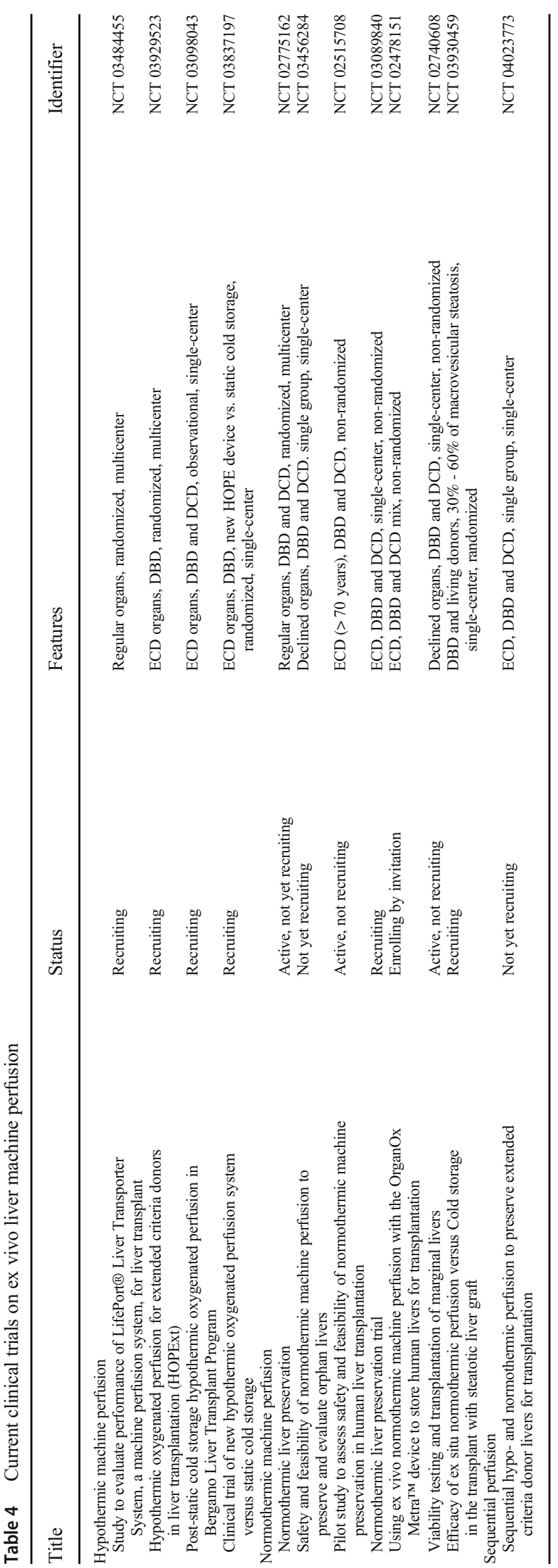

group ( $p=0.08)$ [58]. Of note, similar to the report of Bral et al. [57], NEVLP once again demonstrated improvements of transplantation logistics with $71 \%$ of pSCS-NEVLP liver transplantations initiated during the daytime ( 8 a.m. to 8 p.m.) [58].

The clinical feasibility of the technique was further demonstrated by the Pisa (ITA) and the Innsbruck (AUT) group $[59,60]$ : Ghinolfi et al. used a pSCS-NEVLP approach in a randomized single-center trial comparing NEVLP with SCS for grafts from elderly donors [59]. In the study, 20 grafts retrieved from donors of 70 years of age or older were randomized to pSCS-NEVLP or SCS and eventually transplanted. The primary endpoint was 6-month patient and graft survival and showed non-inferiority of NEVLP preservation [59]. Although histological findings associated NEVLP with a reduction of IRI, no significant differences in clinical outcomes were observed [59]. Cardini et al. recently reported the introduction of routine use of pSCS-NEVLP for marginal donors, logistical challenges, and for complex recipients at the University Hospital of Innsbruck (AUT) [60]. The authors describe a multidisciplinary approach to NEVLP and the establishment of a 24/7 applicable clinical protocol. Analyzing the first 35 cases, the authors report a major improvement in logistics through prolongation of preservation times of up to $30 \mathrm{~h}$, allowing reduction of simultaneous operations and omitting nighttime transplantations. Of the first 35 cases, 25 were transplanted with a patient survival of $88 \%$ at a mean follow-up of $8.6( \pm 5.9)$ months. Of these, $90 \%$ of the grafts were ECD [60].

Compared with SCS and HMP approaches, NEVLP permits graft preservation in a metabolically active state, not only reducing ischemic times but also allowing for ex situ assessment of graft metabolism. Different suggestions for viability criteria have been made, although clinical evaluation is still pending [35-37, 61, 62]. To date, reported viability assessments during NEVLP is based on a holistic interpretation of different perfusion parameters such as lactate clearance, bile production, perfusate $\mathrm{pH}$, glucose metabolism, flow rates, and perfusate transaminases. In addition to the findings of Nasralla et al., where NEVLP lead to a lower discard rate in grafts randomized to NEVLP [54], Cardini et al. reported that the possibility of graft evaluation via NEVLP led to increased consideration of grafts [60]. In 2016, Mergental et al. reported successful transplantation of five liver grafts declined by all the UK centers, after viability assessment (lactate clearance, bile production, perfusate $\mathrm{pH}$, hepatic artery and portal vein flows, and homogeneity of graft perfusion) via NEVLP [36]. Patient survival was $100 \%$ after a 6-19 month follow-up, with no case of PNF reported [36]. A further trial investigating the use of NEVLP for viability assessment in high-risk ECD grafts was published by Watson et al. (2017) [37]. The trial reported transplantation of 12 livers assessed by NEVLP. Median donor risk index was 2.15 (1.47-3.14) with two grafts 
being allocated through an offer for research. Although the study reported adverse outcomes in their initial phase (observing post reperfusion syndrome in 5 of 6 grafts with one case of PNF), reevaluation of their perfusion protocol led to adjustments in oxygenation and allowed subsequent uneventful perfusions and graft evaluation which was uneventful [37]. Specifically, changes in lactate, glucose, and transaminase concentrations, as well as maintenance of perfusate $\mathrm{pH}$, were used for viability assessment and led to 1-year graft and patient survivals of $83 \%$ and $92 \%$ respectively [37]. Most recently, Mergental et al. reported on the outcomes of the VITTAL clinical trial (ClinicalTrials.gov NCT02740608), in which declined liver grafts were assessed by NEVLP. Included grafts must have been declared unsuitable by all the UK transplant centers in addition to meeting one of seven predefined high-risk criteria (e.g., graft macrosteatosis $>30 \%$ or peak donor transaminases $>1000 \mathrm{U} / \mathrm{ml}$ ). Viability assessment was based on lactate clearance below $2.5 \mathrm{mmol} / 1$ within the first 4 hours of NEVLP alongside fulfillment of two or more further criteria, such as bile production, perfusate $\mathrm{pH}$ $\geq 7.3$, metabolism of glucose, HA flow $\geq 150 \mathrm{ml} / \mathrm{min}$ and PV flow $\geq 500 \mathrm{ml} / \mathrm{min}$, or homogenous perfusion. Of 31 assessed grafts, 22 met criteria and were eventually transplanted reaching 100\% 90-day patient and graft survival [63].

\section{Sequential machine perfusion}

While hypothermic machine preservation targets consistent graft temperatures below $10{ }^{\circ} \mathrm{C}$ and NEVLP aims to keep perfusion at physiologic body temperatures, a more dynamic approach towards modulating perfusion temperatures has also been utilized: In 2016, Hoyer et al. demonstrated safety and feasibility for controlled oxygenated rewarming (COR) in a series of six liver transplantations [64]. In this study, SCS grafts were assigned to oxygenated, dual-vessel, ex vivo machine perfusion, for 90 min preceding implantation. Machine perfusion was used to slowly warm grafts before implantation by raising perfusate temperatures from $10{ }^{\circ} \mathrm{C}$ to $20{ }^{\circ} \mathrm{C}$ throughout perfusion. Patient and graft survival were $100 \%$ after 6-month follow-up and COR grafts demonstrated, decreased levels of peak transaminases in the post-operative period (AST $p=0.023$; ALT $p=0.038$ ) [64]. Recently, the group published long-term outcomes of grafts treated with COR preceding transplantation, extending the initial series by 12 patients up to a total of 18 cases, and reporting 1-, 3-, and 5-year patient survival rates of $100 \%, 100 \%$, and $93.8 \%$, respectively [65]. A trial published by van Leeuwen et al. in 2019 further aimed to combine the beneficial features of DHOPE and NEVLP for graft resuscitation and viability assessment, in a study of nationwide declined grafts [35]. In the trial HBOC-201, a hemoglobin-based, cell free oxygen carrier was used for substitution of red blood cells, allowing uninterrupted transition from a D-HOPE phase over a period of COR to
NEVLP. Grafts were transported in SCS to the study center and evaluated during NEVLP. Grafts that met predefined viability criteria (perfusate lactate $<1.7 \mathrm{mmol} / \mathrm{L} ; \mathrm{pH} 7.35$ to 7.45 ; bile-production $>10 \mathrm{~mL}$; bile $\mathrm{pH}>7.45$ ) were subsequently transplanted [35]. Of the 16 perfused livers studied, 11 ultimately met viability criteria and thus were transplanted, with $100 \%$ patient and graft survival at 3 and 6 months, respectively. All transplanted grafts were obtained from DCD donors with a median Eurotransplant donor risk index (ETDRI) of 2.82 (2.6-2.9). During the study period, graft evaluation by machine perfusion led to an increase of deceased donor liver transplantation by $20 \%$ in the study center [35].

\section{Ongoing clinical trials}

Currently, 12 studies investigating the role of machine perfusion in liver transplantation are enrolled in the ClinicalTrials. gov registry. There are a greater number of studies using a normothermic approach $(n=7)$ compared with those using hypothermic perfusion $(n=4)$. Sequential hypothermic to normothermic machine perfusion is being investigated in one single-center prospective pilot study, registered by the Cleveland Clinic (Ohio, USA) group. Of the hypothermic approach, two are randomized multicenter trials, of which one uses regular liver grafts, while the other focuses on ECD DBD grafts. Regarding currently active studies investigating NEVLP, the objective of all except one is the assessment of the effect of NEVLP vs. SCS on ECD liver grafts. Interestingly, two of the enrolled trials target assessment and resuscitation of declined liver grafts by NEVLP, applying viability criteria such as lactate clearance and bile production.

\section{Discussion}

Over the last 5 years, the burgeoning number of published and ongoing clinical trials investigating ex vivo machine perfusion in liver transplantation reflects a renewed interest of this platform technology. Challenging the long-time paradigm of static cold storage of liver grafts in ice boxes, ex vivo liver machine perfusion holds promise as a method to increase the safety and utilization of marginal livers for transplantation. This might be achieved not only through viability assessment of high-risk grafts but also through reconditioning of otherwise unusable liver grafts.

Review of the current literature suggests that ex vivo liver perfusion, at hypothermic as well as normothermic perfusate temperatures, reduces preservation injury in standard criteria grafts. This observation is supported by a reduced incidence of EAD and decreased levels of peak transaminases. However, whether machine perfusion of a standard graft is necessary remains to be answered as no mortality benefit was noted compared with patients undergoing transplantation of 
standard criteria SCS liver grafts. Due to its high costs, application for pre-defined indications might facilitate adoption and maximize the benefit of ex vivo liver machine perfusion in broader clinical practice. As reported by the Zürich group, HOPE allowed reintroduction of DCD liver transplantation, showing improved outcomes regarding intrahepatic cholangiopathy compared with matched SCS DCD grafts and thus expanded their donor pool [48]. Although data from randomized controlled trials on HOPE have not been reported as of yet, current literature suggests its superiority towards classic SCS, raising the question as to whether this technically and logistically less demanding technology (compared with NEVLP) might evolve for routine use in standard criteria donors, especially in cases with expected prolonged hepatectomy times.

An increasing number of studies reported application of ex vivo machine perfusion in extended criteria donors and suggests beneficial effects regarding EAD may be achieved by both the hypothermic and normothermic approach. The Zürich group observed better outcomes in a series of HOPEtreated steatotic grafts, when compared with a cohort of SCS fatty liver transplantations [50]. Furthermore, the Pisa group reported histological evidence of reduced IRI after NEVLP of grafts from donors older than 70 years of age in a single-center randomized controlled trial [59]. Although the evidence for positive effects of machine perfusion on marginal grafts is still limited, the interest continues to grow as reflected by the number of ongoing clinical trials. Given the current demographic change in the western world and the projected dramatic incidence of hepatic steatosis in the donor pool, ex vivo liver machine perfusion might be an ideal tool for preservation of marginal liver grafts prior transplantation. [66, 67].

To fully exploit the potential of ex vivo machine perfusion for marginal grafts, further insight in the underlying mechanisms of the effects of machine perfusion on liver physiology and metabolism remains paramount. For instance, Lai et al. concluded in a systematic review, assessing ex vivo liver machine perfusion before transplantation in 54 cases of grafts affected by macrovesicular steatosis (24\% showing moderate to severe steatosis $[\geq 30 \%]$ ) that no differences in clinical outcome such as post-transplant death or severe complications following machine perfusion could be identified. Raigani et al. have demonstrated that steatotic liver grafts suffer from deficits in antioxidant capacity, efficient energy utilization, and lipid metabolism during normothermic liver machine perfusion. [68]. Thus, although the near physiologic state maintained by NEVLP is beneficial in and of itself, it may additionally serve as a platform to allow further optimization of marginal liver grafts by drug application during ex vivo machine perfusion. Currently, several groups are working on protocols for "defatting" of steatotic liver grafts, with the idea of decreasing the detrimental effect of IRI on these organs after reperfusion [69-71]. Indeed, a recently published report of the Zürich group, preserving injured human livers for 7 days by ex vivo machine perfusion, encourages research towards drug application as the available period for ex vivo drug treatment is significantly prolonged [72]. It must still be evaluated if further marginality criteria, e.g., extended age of the donor, might also be addressed during ex vivo machine perfusion. So far, it is unknown whether these organs have specific needs that could be met during perfusion or not. The currently ongoing trials will hopefully provide insight of the impact machine perfusion has on marginal liver grafts by providing not only clinical data but also biologic samples to address those questions. Beyond these applications, machine perfusion offers even broader possibilities such as HCV clearance with existing drugs as has already been proposed experimentally [73]. Transfection with viral vectors or siRNA may also allow for immunomodulation and reduced immunosuppression [74, 75]. Infusion of mesenchymal stem cells can ameliorate preexisting damages such as warm ischemia [76]. Even genetic modulation during machine perfusion may lead to a new frontier in the field of transplantation medicine and advanced treatments allowing for engineered or personalized grafts. As the drugs or agents are applied ex vivo, they are unaffected by the humoral and cellular immune system and can be washed from the liver at the end of perfusion, thus allowing for potential use of treatments not feasible in vivo.

When comparing hypothermic and normothermic machine perfusion approaches, it is important to note that normothermic systems enable metabolic characterization and viability assessment of the grafts by "simple" read out parameters like bile production, bile $\mathrm{pH}$, or lactate clearance, while reduced metabolic activity during hypothermia restricts the viability assessment capacity of HMP systems. Although specific surrogate parameters or biomarkers might be able to fill this gap, as shown by Muller et al. [77], normothermic approaches simulate near physiologic conditions allowing for use of classic clinical parameters for graft evaluation. A European multicenter-randomized controlled trial showed significantly lower discard rates in grafts randomized to the NEVLP arm [54]. Moreover, van Leeuven et al. and Mergental et al. reported "resuscitation" and successful transplantation of declined liver grafts after back-to-base machine perfusion. Assessing pre-defined viability criteria during the normothermic perfusion phase, both groups achieved high 1-year graft survivals of livers initially declined for transplantation [35, 63].

Lastly, as success in transplantation remains dependent on multidisciplinary care, decreasing strain on treatment teams remains important. By allowing for prolonged preservation periods up to $30 \mathrm{~h}$ [60], NEVLP has improved operating room logistics by permitting more daytime transplantations as reported by three groups $[57,58,60]$. Inherently, this provides for increased availability of experienced staff across disciplines, [60] and has the potential to further optimize outcomes and decrease failure to rescue after liver transplantation. 
In line with our conclusions, the Italian Society of Organ and Tissue Transplantation (SITO) recently released their evidence-based position paper on machine perfusion in liver transplantation [78], recommending the consideration of HMP and NEVLP as safe techniques for organ preservation and suggesting its use for reduction of post-transplant EAD. Furthermore, it recognized hypothermic- and normothermic-machine perfusion as useful tools for prolongation of ex vivo times and improvement of transplantation logistics. HMP was suggested as useful for improvement of graft survival in ECD and DCD donors and for reduction of ischemic type biliary lesions. NEVLP was considered useful for the implementation of the use of ECD donors, by allowing evaluation of graft function and highlighting the potential of NEVLP for ex vivo viability assessment [78].

In conclusion, ex vivo liver machine perfusion has significant potential to revolutionize the field of liver transplantation. In a field challenged by a persistent organ shortage and continued donor demographic changes threatening the quality of the already scarce pool of available grafts, the use of this technology may help in addressing the daunting waitlist mortality. Within its first decade of clinical introduction, it has proven to be safe and feasible, for hypothermic and normothermic perfusate temperatures, and demonstrated improved early graft function, compared with SCS preserved grafts. These findings have allowed reintroduction of DCD programs in countries with long mandatory no touch periods and salvage of grafts that otherwise would have been discarded. Considering the early stage of the technology, it remains critical to gain further insight into the underlying mechanisms that lead to observed clinical change, and the possibility of expanding use of this technique for treatment and reconditioning of otherwise unusable donor grafts.

Authors' contributions Julian Michelotto: acquisition of data, analysis and interpretation of data, and drafting of manuscript. Joseph MGV Gassner: study conception and design, acquisition of data, analysis and interpretation of data, and drafting of manuscript. Simon Moosburner: acquisition of data, analysis and interpretation of data, and drafting of manuscript. Vanessa Muth: acquisition of data, analysis and interpretation of data, and drafting of manuscript. Madhukar S Patel: acquisition of data, analysis and interpretation of data, and critical revision of manuscript. Markus Selzner: drafting of manuscript and critical revision of manuscript. Johann Pratschke: drafting of manuscript and critical revision of manuscript. Igor M. Sauer: drafting of manuscript and critical revision of manuscript. Nathanael Raschzok: study conception and design, acquisition of data, analysis and interpretation of data, drafting of manuscript, and critical revision of manuscript.

Funding Open Access funding enabled and organized by Projekt DEAL.

\section{Compliance with ethical standards}

Conflict of interest The authors declare that they have no conflict of interest.

Ethical approval All procedures performed in the reported studies involving human participants were in accordance with the ethical standards of their institutional and/or national research committee and with the 1964 Helsinki declaration and its later amendments or comparable ethical standards.

Open Access This article is licensed under a Creative Commons Attribution 4.0 International License, which permits use, sharing, adaptation, distribution and reproduction in any medium or format, as long as you give appropriate credit to the original author(s) and the source, provide a link to the Creative Commons licence, and indicate if changes were made. The images or other third party material in this article are included in the article's Creative Commons licence, unless indicated otherwise in a credit line to the material. If material is not included in the article's Creative Commons licence and your intended use is not permitted by statutory regulation or exceeds the permitted use, you will need to obtain permission directly from the copyright holder. To view a copy of this licence, visit http://creativecommons.org/licenses/by/4.0/.

\section{References}

1. Dutkowski P, Linecker M, DeOliveira ML, Müllhaupt B, Clavien PA (2015) Challenges to liver transplantation and strategies to improve outcomes. Gastroenterology 148(2):307-323

2. Lai JC, Feng S, Roberts JP (2012) An examination of liver offers to candidates on the liver transplant wait-list. Gastroenterology 143(5):1261-1265

3. Detelich D, Markmann JF (2018) The dawn of liver perfusion machines. Curr Opin Organ Transplant 23(2):151-161

4. Ceresa CDL, Nasralla D, Knight S, Friend PJ (2017) Cold storage or normothermic perfusion for liver transplantation: probable application and indications. Curr Opin Organ Transplant 22(3):300-305

5. Durand F, Renz JF, Alkofer B, Burra P, Clavien PA, Porte RJ, Freeman RB, Belghiti J (2008) Report of the Paris consensus meeting on expanded criteria donors in liver transplantation. Liver Transpl 14(12):1694-1707

6. Routh D, Naidu S, Sharma S, Ranjan P, Godara R (2013) Changing pattern of donor selection criteria in deceased donor liver transplant: a review of literature. J Clin Exp Hepatol 3(4):337-346

7. Barshes NR, Horwitz IB, Franzini L, Vierling JM, Goss JA (2007) Waitlist mortality decreases with increased use of extended criteria donor liver grafts at adult liver transplant centers. Am J Transplant 7(5):1265-1270

8. Tector AJ, Mangus RS, Chestovich P, Vianna R, Fridell JA, Milgrom ML, Sanders C, Kwo PY (2006) Use of extended criteria livers decreases wait time for liver transplantation without adversely impacting posttransplant survival. Ann Surg 244(3):439-450

9. Renz JF et al (2005) Utilization of extended donor criteria liver allografts maximizes donor use and patient access to liver transplantation. Ann Surg 242(4):556-563 discussion 563-5

10. Moosburner S, Sauer IM, Gassner JMGV, Schleicher C, Bösebeck D, Rahmel A, Pratschke J, Raschzok N (2019) Macrosteatosis is a huge problem in liver transplantation-however, not the only one we face. Am J Transplant 19(9):2661-2662

11. Busuttil RW, Tanaka K (2003) The utility of marginal donors in liver transplantation. Liver Transpl 9(7):651-663 
12. Nocito A, El-Badry AM, Clavien PA (2006) When is steatosis too much for transplantation? J Hepatol 45(4):494-499

13. Spitzer AL, Lao OB, Dick AAS, Bakthavatsalam R, Halldorson JB, Yeh MM, Upton MP, Reyes JD, Perkins JD (2010) The biopsied donor liver: incorporating macrosteatosis into high-risk donor assessment. Liver Transpl 16(7):874-884

14. Dutkowski P, Schlegel A, Slankamenac K, Oberkofler CE, Adam R, Burroughs AK, Schadde E, Müllhaupt B, Clavien PA (2012. discussion 868-9) The use of fatty liver grafts in modern allocation systems: risk assessment by the balance of risk (BAR) score. Ann Surg 256(5):861-868

15. Mathur AK, Heimbach J, Steffick DE, Sonnenday CJ, Goodrich NP, Merion RM (2010) Donation after cardiac death liver transplantation: predictors of outcome. Am J Transplant 10(11):25122519

16. Jimenez-Romero C et al (2014) Using old liver grafts for liver transplantation: where are the limits? World J Gastroenterol 20(31):10691-10702

17. Uemura T, Nikkel LE, Hollenbeak CS, Ramprasad V, Schaefer E, Kadry Z (2012) How can we utilize livers from advanced aged donors for liver transplantation for hepatitis C? Transpl Int 25(6): 671-679

18. Dasari BVM, Schlegel A, Mergental H, Perera MTPR (2017) The use of old donors in liver transplantation. Best Pract Res Clin Gastroenterol 31(2):211-217

19. Cohen JC, Horton JD, Hobbs HH (2011) Human fatty liver disease: old questions and new insights. Science 332(6037):1519-1523

20. European association for the study of the liver. Electronic address, e.e.e (2016) EASL Clinical Practice Guidelines: Liver transplantation. J Hepatol 64(2):433-485

21. Tengda $\mathrm{H}$ et al (2012) Effect of steatosis donor liver transplantation on hepatocellular carcinoma recurrence: experience at a single institution. Hepatogastroenterology 59(115):858-862

22. de Graaf EL, Kench J, Dilworth P, Shackel NA, Strasser SI, Joseph D, Pleass H, Crawford M, McCaughan GW, Verran DJ (2012) Grade of deceased donor liver macrovesicular steatosis impacts graft and recipient outcomes more than the Donor Risk Index. J Gastroenterol Hepatol 27(3):540-546

23. Clark JM, Brancati FL, Diehl AM (2002) Nonalcoholic fatty liver disease. Gastroenterology 122(6):1649-1657

24. Parekh S, Anania FA (2007) Abnormal lipid and glucose metabolism in obesity: implications for nonalcoholic fatty liver disease. Gastroenterology 132(6):2191-2207

25. Zhang QY, Zhang QF, Zhang DZ (2019) The impact of steatosis on the outcome of liver transplantation: a meta-analysis. Biomed Res Int 2019:3962785

26. Chu MJ et al (2015) Donor hepatic steatosis and outcome after liver transplantation: a systematic review. J Gastrointest Surg 19(9): $1713-1724$

27. Nemes B, Gámán G, Polak WG, Gelley F, Hara T, Ono S, Baimakhanov Z, Piros L, Eguchi S (2016) Extended-criteria donors in liver transplantation part II: reviewing the impact of extendedcriteria donors on the complications and outcomes of liver transplantation. Expert Rev Gastroenterol Hepatol 10(7):841-859

28. Abt PL, Desai NM, Crawford MD, Forman LM, Markmann JW, Olthoff KM, Markmann JF (2004) Survival following liver transplantation from non-heart-beating donors. Ann Surg 239(1):87-92

29. D'Alessandro AM et al (2000) Liver transplantation from controlled non-heart-beating donors. Surgery 128(4):579-588

30. Ploeg RJ et al (1993) Risk factors for primary dysfunction after liver transplantation-a multivariate analysis. Transplantation 55(4):807813

31. O'Neill S, Roebuck A, Khoo E, Wigmore SJ, Harrison EM (2014) A meta-analysis and meta-regression of outcomes including biliary complications in donation after cardiac death liver transplantation. Transpl Int 27(11):1159-1174
32. Jay C, Ladner D, Wang E, Lyuksemburg V, Kang R, Chang Y, Feinglass J, Holl JL, Abecassis M, Skaro AI (2011) A comprehensive risk assessment of mortality following donation after cardiac death liver transplant - an analysis of the national registry. J Hepatol 55(4):808-813

33. Taner CB, Bulatao IG, Perry DK, Sibulesky L, Willingham DL, Kramer DJ, Nguyen JH (2012) Asystole to cross-clamp period predicts development of biliary complications in liver transplantation using donation after cardiac death donors. Transpl Int 25(8):838846

34. Chan EY, Olson LC, Kisthard JA, Perkins JD, Bakthavatsalam R, Halldorson JB, Reyes JD, Larson AM, Levy AE (2008) Ischemic cholangiopathy following liver transplantation from donation after cardiac death donors. Liver Transpl 14(5):604-610

35. van Leeuwen OB, de Vries Y, Fujiyoshi M, Nijsten MWN, Ubbink R, Pelgrim GJ, Werner MJM, Reyntjens KMEM, van den Berg AP, de Boer MT, de Kleine RHJ, Lisman T, de Meijer VE, Porte RJ (2019) Transplantation of high-risk donor livers after ex situ resuscitation and assessment using combined hypo- and normothermic machine perfusion: a prospective clinical trial. Ann Surg 270(5): 906-914

36. Mergental H, Perera MTPR, Laing RW, Muiesan P, Isaac JR, Smith A, Stephenson BTF, Cilliers H, Neil DAH, Hübscher SG, Afford SC, Mirza DF (2016) Transplantation of declined liver allografts following normothermic ex-situ evaluation. Am J Transplant 16(11):3235-3245

37. Watson CJE, Kosmoliaptsis V, Randle LV, Gimson AE, Brais R, Klinck JR, Hamed M, Tsyben A, Butler AJ (2017) Normothermic perfusion in the assessment and preservation of declined livers before transplantation: hyperoxia and vasoplegia-important lessons from the first 12 cases. Transplantation 101(5):1084-1098

38. Henry SD, Nachber E, Tulipan J, Stone J, Bae C, Reznik L, Kato T, Samstein B, Emond JC, Guarrera JV (2012) Hypothermic machine preservation reduces molecular markers of ischemia/reperfusion injury in human liver transplantation. Am J Transplant 12(9):24772486

39. Guarrera JV, Henry SD, Chen SWC, Brown T, Nachber E, Arrington B, Boykin J, Samstein B, Brown RS Jr, Emond JC, Lee HT (2011) Hypothermic machine preservation attenuates ischemia/reperfusion markers after liver transplantation: preliminary results. J Surg Res 167(2):e365-e373

40. Karangwa SA, Dutkowski P, Fontes P, Friend PJ, Guarrera JV, Markmann JF, Mergental H, Minor T, Quintini C, Selzner M, Uygun K, Watson CJ, Porte RJ (2016) Machine perfusion of donor livers for transplantation: a proposal for standardized nomenclature and reporting guidelines. Am J Transplant 16(10):2932-2942

41. Schlegel A, Kron P, Dutkowski P (2016) Hypothermic machine perfusion in liver transplantation. Curr Opin Organ Transplant 21(3):308-314

42. Kollmann D, Selzner M (2017) Recent advances in the field of warm ex-vivo liver perfusion. Curr Opin Organ Transplant 22(6): $555-562$

43. Patrono D et al (2018) Hypothermic oxygenated machine perfusion for liver transplantation: an initial experience. Exp Clin Transplant 16(2):172-176

44. Dondossola D, Lonati C, Zanella A, Maggioni M, Antonelli B, Reggiani P, Gatti S, Rossi G (2019) Preliminary experience with hypothermic oxygenated machine perfusion in an Italian liver transplant center. Transplant Proc 51(1):111-116

45. van Rijn R, Karimian N, Matton APM, Burlage LC, Westerkamp AC, van den Berg AP, de Kleine RHJ, de Boer MT, Lisman T, Porte RJ (2017) Dual hypothermic oxygenated machine perfusion in liver transplants donated after circulatory death. Br J Surg 104(7): 907-917

46. Guarrera JV, Henry SD, Samstein B, Odeh-Ramadan R, Kinkhabwala M, Goldstein MJ, Ratner LE, Renz JF, Lee HT, 
Brown RS Jr, Emond JC (2010) Hypothermic machine preservation in human liver transplantation: the first clinical series. Am J Transplant 10(2):372-381

47. Guarrera JV, Henry SD, Samstein B, Reznik E, Musat C, Lukose TI, Ratner LE, Brown RS Jr, Kato T, Emond JC (2015) Hypothermic machine preservation facilitates successful transplantation of "orphan" extended criteria donor livers. Am J Transplant 15(1):161-169

48. Dutkowski P, Schlegel A, de Oliveira M, Müllhaupt B, Neff F, Clavien PA (2014) HOPE for human liver grafts obtained from donors after cardiac death. J Hepatol 60(4):765-772

49. Dutkowski P, Polak WG, Muiesan P, Schlegel A, Verhoeven CJ, Scalera I, DeOliveira ML, Kron P, Clavien PA (2015) First comparison of hypothermic oxygenated PErfusion versus static cold storage of human donation after cardiac death liver transplants: an international-matched case analysis. Ann Surg 262(5):764-770 discussion 770-1

50. Kron P et al (2017) Hypothermic oxygenated perfusion (HOPE) for fatty liver grafts in rats and humans. J Hepatol 21:S01688278(17)32268-7. https://doi.org/10.1016/j.jhep.2017.08.028

51. Ravikumar R, Jassem W, Mergental H, Heaton N, Mirza D, Perera MTPR, Quaglia A, Holroyd D, Vogel T, Coussios CC, Friend PJ (2016) Liver transplantation after ex vivo normothermic machine preservation: a phase 1 (first-in-man) clinical trial. Am J Transplant 16(6):1779-1787

52. Selzner M, Goldaracena N, Echeverri J, Kaths JM, Linares I, Selzner N, Serrick C, Marquez M, Sapisochin G, Renner EL, Bhat M, McGilvray ID, Lilly L, Greig PD, Tsien C, Cattral MS, Ghanekar A, Grant DR (2016) Normothermic ex vivo liver perfusion using Steen solution as perfusate for human liver transplantation: first North American results. Liver Transpl 22(11):1501-1508

53. Bral M, Gala-Lopez B, Bigam D, Kneteman N, Malcolm A, Livingstone S, Andres A, Emamaullee J, Russell L, Coussios C, West LJ, Friend PJ, Shapiro AMJ (2017) Preliminary single-center Canadian experience of human normothermic ex vivo liver perfusion: results of a clinical trial. Am J Transplant 17(4):1071-1080

54. Nasralla D et al (2018) A randomized trial of normothermic preservation in liver transplantation. Nature 557(7703):50-56

55. Liu Q, Hassan A, Pezzati D, Soliman B, Lomaglio L, Grady P, del Angel Diaz L, Simioni A, Maikhor S, Etterling J, D'Amico G, Iuppa G, Diago Uso T, Hashimoto K, Aucejo F, Fujiki M, Eghtesad B, Sasaki K, Kwon CHD, Cywinski J, Irefin S, Bennett A, Baldwin W, Miller C, Quintini C (2020) Ex situ liver machine perfusion: the impact of fresh frozen plasma. Liver Transpl 26(2): 215-226

56. Reddy S, Greenwood J, Maniakin N, Bhattacharjya S, Zilvetti M, Brockmann J, James T, Pigott D, Friend P (2005) Non-heartbeating donor porcine livers: the adverse effect of cooling. Liver Transpl 11(1):35-38

57. Bral M, Dajani K, Leon Izquierdo D, Bigam D, Kneteman N, Ceresa CDL, Friend PJ, Shapiro AMJ (2019) A back-to-base experience of human normothermic ex situ liver perfusion: does the chill kill? Liver Transpl 25(6):848-858

58. Ceresa CDL, Nasralla D, Watson CJE, Butler AJ, Coussios CC, Crick K, Hodson L, Imber C, Jassem W, Knight SR, Mergental H, Ploeg RJ, Pollok JM, Quaglia A, Shapiro AMJ, Weissenbacher A, Friend PJ (2019) Transient cold storage prior to normothermic liver perfusion may facilitate adoption of a novel technology. Liver Transpl 25:1503-1513

59. Ghinolfi D, Rreka E, de Tata V, Franzini M, Pezzati D, Fierabracci V, Masini M, Cacciatoinsilla A, Bindi ML, Marselli L, Mazzotti V, Morganti R, Marchetti P, Biancofiore G, Campani D, Paolicchi A, de Simone P (2019) Pilot, open, randomized, prospective trial for normothermic machine perfusion evaluation in liver transplantation from older donors. Liver Transpl 25(3):436-449
60. Cardini B et al (2020) Clinical implementation of prolonged liver preservation and monitoring through Normothermic machine perfusion in liver transplantation. Transplantation 104(9):1917-1928. https://doi.org/10.1097/TP.0000000000003296

61. Mergental H, Stephenson BTF, Laing RW, Kirkham AJ, Neil DAH, Wallace LL, Boteon YL, Widmer J, Bhogal RH, Perera MTPR, Smith A, Reynolds GM, Yap C, Hübscher SG, Mirza DF, Afford SC (2018) Development of clinical criteria for functional assessment to predict primary nonfunction of high-risk livers using normothermic machine perfusion. Liver Transpl 24(10): 1453-1469

62. Sutton ME, op den Dries S, Karimian N, Weeder PD, de Boer MT, Wiersema-Buist J, Gouw ASH, Leuvenink HGD, Lisman T, Porte RJ (2014) Criteria for viability assessment of discarded human donor livers during ex vivo normothermic machine perfusion. PLoS One 9(11):e110642

63. Mergental H, Laing RW, Kirkham AJ, Perera MTPR, Boteon YL, Attard J, Barton D, Curbishley S, Wilkhu M, Neil DAH, Hübscher SG, Muiesan P, Isaac JR, Roberts KJ, Abradelo M, Schlegel A, Ferguson J, Cilliers H, Bion J, Adams DH, Morris C, Friend PJ, Yap C, Afford SC, Mirza DF (2020) Transplantation of discarded livers following viability testing with normothermic machine perfusion. Nat Commun 11(1):2939

64. Hoyer DP, Mathé Z, Gallinat A, Canbay AC, Treckmann JW, Rauen U, Paul A, Minor T (2016) Controlled oxygenated rewarming of cold stored livers prior to transplantation: first clinical application of a new concept. Transplantation 100(1):147-152

65. Hoyer DP, Benkö T, Manka P, von Horn C, Treckmann JW, Paul A, Minor T (2020) Long-term outcomes after controlled oxygenated rewarming of human livers before transplantation. Transplant Direct 6(4):e542

66. Pais R, Barritt AS 4th, Calmus Y, Scatton O, Runge T, Lebray P, Poynard T, Ratziu V, Conti F (2016) NAFLD and liver transplantation: current burden and expected challenges. J Hepatol 65(6): $1245-1257$

67. Parikh ND, Hutton D, Marrero W, Sanghani K, Xu Y, Lavieri M (2015) Projections in donor organs available for liver transplantation in the United States: 2014-2025. Liver Transpl 21(6):855-863

68. Raigani S, Karimian N, Huang V, Zhang AM, Beijert I, Geerts S, Nagpal S, Hafiz EOA, Fontan FM, Aburawi MM, Mahboub P, Markmann JF, Porte RJ, Uygun K, Yarmush M, Yeh H (2020) Metabolic and lipidomic profiling of steatotic human livers during ex situ normothermic machine perfusion guides resuscitation strategies. PLoS One 15(1):e0228011

69. Nagrath $\mathrm{D}, \mathrm{Xu} \mathrm{H}$, Tanimura $\mathrm{Y}$, Zuo R, Berthiaume F, Avila M, Yarmush R, Yarmush ML (2009) Metabolic preconditioning of donor organs: defatting fatty livers by normothermic perfusion ex vivo. Metab Eng 11(4-5):274-283

70. Boteon YL, Attard J, Boteon APCS, Wallace L, Reynolds G, Hubscher S, Mirza DF, Mergental H, Bhogal RH, Afford SC (2019) Manipulation of lipid metabolism during normothermic machine perfusion: effect of defatting therapies on donor liver functional recovery. Liver Transpl 25(7):1007-1022

71. Raigani S, Carroll C, Griffith S, Pendexter C, Rosales I, Deirawan $\mathrm{H}$, Beydoun R, Yarmush M, Uygun K, Yeh H (2020) Improvement of steatotic rat liver function with a defatting cocktail during ex situ normothermic machine perfusion is not directly related to liver fat content. PLoS One 15(5):e0232886

72. Eshmuminov D, Becker D, Bautista Borrego L, Hefti M, Schuler MJ, Hagedorn C, Muller X, Mueller M, onder C, Graf R, Weber A, Dutkowski P, Rudolf von Rohr P, Clavien PA (2020) An integrated perfusion machine preserves injured human livers for 1 week. Nat Biotechnol 38(2):189-198

73. Goldaracena N, Spetzler VN, Echeverri J, Kaths JM, Cherepanov V, Persson R, Hodges MR, Janssen HLA, Selzner N, Grant DR, Feld JJ, Selzner M (2017) Inducing hepatitis C virus resistance after 
pig liver transplantation-a proof of concept of liver graft modification using warm ex vivo perfusion. Am J Transplant 17(4):970-978

74. Bishawi M, Roan JN, Milano CA, Daneshmand MA, Schroder JN, Chiang Y, Lee FH, Brown ZD, Nevo A, Watson MJ, Rowell T, Paul S, Lezberg P, Walczak R, Bowles DE (2019) A normothermic ex vivo organ perfusion delivery method for cardiac transplantation gene therapy. Sci Rep 9(1):8029

75. Gillooly AR, Perry J, Martins PN (2019) First report of siRNA uptake (for RNA interference) during ex vivo hypothermic and normothermic liver machine perfusion. Transplantation 103(3): e56-e57

76. Yang L, Cao H, Sun D, Lin L, Zheng WP, Shen ZY, Song HL (2020) Normothermic machine perfusion combined with bone marrow mesenchymal stem cells improves the oxidative stress response and mitochondrial function in rat donation after circulatory death livers. Stem Cells Dev 29:835-852

77. Muller X, Schlegel A, Kron P, Eshmuminov D, Würdinger M, Meierhofer D, Clavien PA, Dutkowski P (2019) Novel real-time prediction of liver graft function during hypothermic oxygenated machine perfusion before liver transplantation. Ann Surg 270(5): 783-790

78. Ghinolfi D, Lai Q, Dondossola D, de Carlis R, Zanierato M, Patrono D, Baroni S, Bassi D, Ferla F, Lauterio A, Lazzeri C, Magistri P, Melandro F, Pagano D, Pezzati D, Ravaioli M, Rreka E, Toti L, Zanella A, Burra P, Petta S, Rossi M, Dutkowski P, Jassem W, Muiesan P, Quintini C, Selzner M, Cillo U, Agnes S, Andorno E, Cescon M, Colledan M, de Carlis L, de Simone P, di
Benedetto F, Maria Ettorre G, Gruttadauria S, Giovanni Lupo L, Mazzaferro V, Baccarani U, Romagnoli R, Rossi G, Spada M, Carraro A, Tisone G, Vennarecci G, Vivarelli M, Zamboni F, Cardillo M, Procaccio F, Corcione A, D'Antonio L, de Pace F, Famulari A, Feltrin G, Gesualdo L, Gianelli Castiglione A, Guermani A, Mancini P, Peressutti A, Peris A, Piazza B, Piccolo G, Pilati L, Sangiorgi G, Saracino A, Torlone N, Zanon P, Boggi U, Amoroso A, Vistoli F, Amarelli C, Biancofiore G, Maggiore U, Santaniello W (2020) Machine perfusions in liver transplantation: the evidence-based position paper of the italian society of organ and tissue transplantation. Liver Transpl 26(10):1298-1315. https://doi. org/10.1002/lt.25817

\section{Disclaimer}

All figures and tables were compiled by the authors themselves for this publication and were not published previously. Text passages and publications that have already been published elsewhere were cited according to good scientific practices.

Publisher's note Springer Nature remains neutral with regard to jurisdictional claims in published maps and institutional affiliations. 